\title{
A Table of Electronic Configurations of the Elements.
}

$\mathrm{M}^{\mathrm{B}}$

R. ROY GARDNER gave an interesting paper on "A Method of Setting out the Clasisification of the Elements" at a recent meeting of the New Zealand Institute. The paper included the accompanying Table, which shows the distribution of are considered to be filled in order to the maxima 2 , divalent ions, the point is of minor interest chemically. Distribution of electrons into $k$-subgroups is unnecessary; these have at present little significance for chemical purposes, and in any case the subgroups are considered to be filled in order to the maxima 2 ,

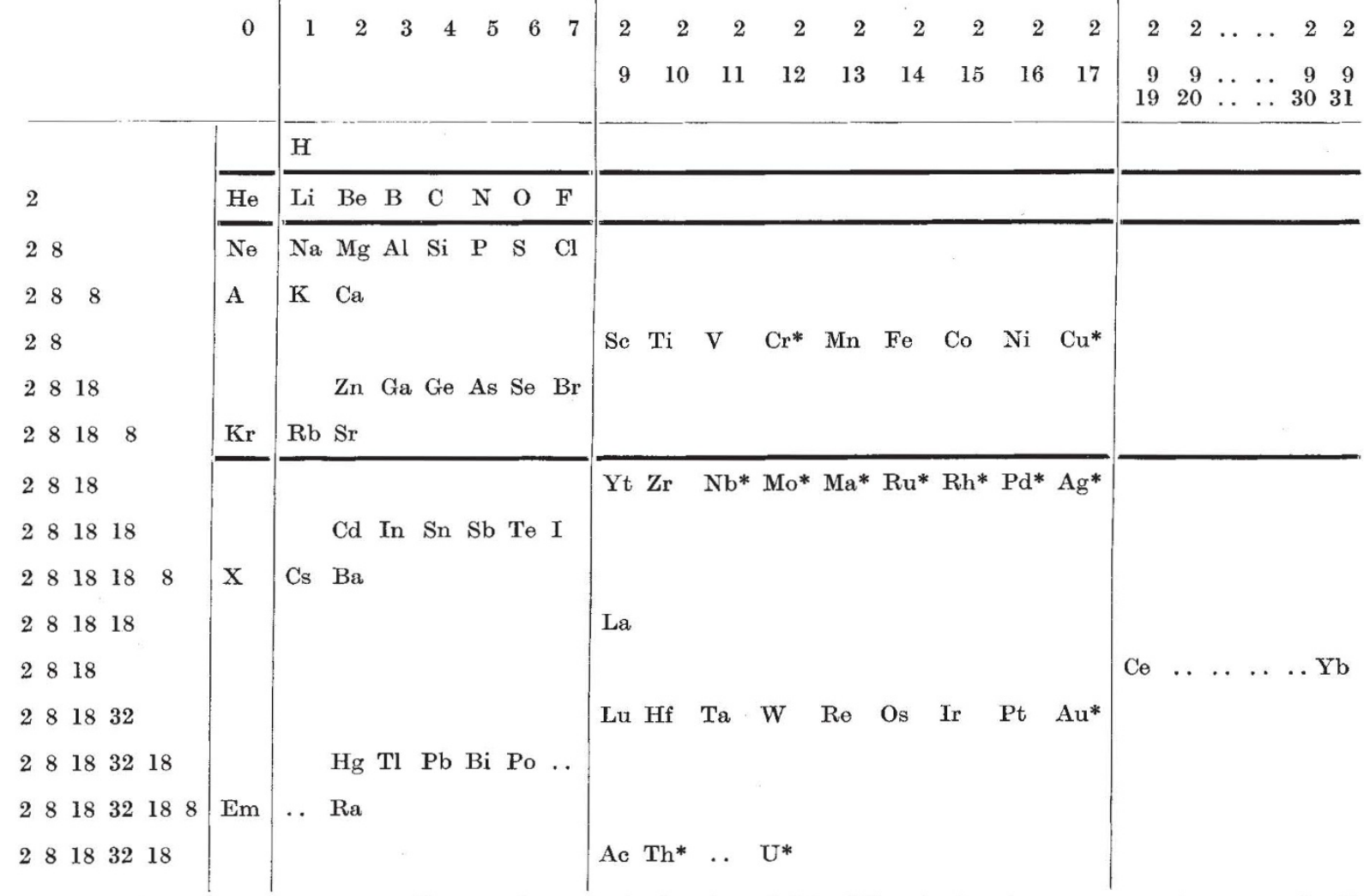

electrons into groups corresponding to the principal quantum numbers for all the elements and at the same time preserves the most essential features of the two-dimensional arrangement of Mendeléef. Elements having the same complete groups (that is, all stable groups of 8 or 18) are placed in the same horizontal row, and the vertical columns include elements with the same number of electrons in the incomplete outer groups. The electronic configurations are those given by Sidgwick ("Electronic Theory of Valency ", 1927). An asterisk marks elements for which the "normal' atom is thought to have only one electron in the outermost group, but as practically all these give
6, and 10. The electronic arrangements are read off as shown by the following examples:

$$
\begin{aligned}
& \text { Sb } 2 ; 8 ; 18 ; 18 ; 5 \\
& \mathrm{Fe} 2 ; 8 ; 14 ; 2 \\
& \mathrm{Ce} 2 ; 8 ; 18 ; 19 ; 9 ; 2 .
\end{aligned}
$$

The existence of four types of elements is emphasised -(1) those with all groups complete; (2) those with one incomplete group; (3) those with two incomplete groups (transition elements); (4) those with three incomplete groups (rare earth elements). The upper limits of existence of covalencies of 8,6 , and 4 are marked by heavy horizontal lines.

\section{Electrical Research in Industry.}

$\mathrm{O}^{\mathrm{N}}$ $\mathrm{NE}$ of the most important functions of the research department of a manufacturing company is to study the development of science with the view of its industrial application. At the beginning of the War there was a wide gulf between research and industry, although it was beginning to get narrowed. In 1915 there was a national movement in Great Britain to accelerate the application of science to industry, and this contributed largely to our industrial progress.

We have received from Messrs. Metropolitan-Vickers Electrical Co., Ltd., of Trafford Park, Manchester, an account of their research activities during 1929 . This bears out how advantageous it is to make full use of scientific methods and the latest scientific develop- ments in industry. An example of this is the development of a low vapour pressure grease for use with vacuum pumps and valves. This has made commercially possible the manufacture of vacuum apparatus which can be taken to pieces. With the highest vacua used at the present time, grease can be used for sealing the joints which has no appreciable evaporation products. The research work on the "creep " of steels and other materials has led to important results. Apparatus has been made which enables the creep characteristics to be determined immediately by comparison with a standard up to temperatures of $800^{\circ} \mathrm{C}$. The study of the rates of strain has enabled a tolerance limit to be fixed in turbine construction. The effect of combina-

No. 3143 , VoL. 125] 